\title{
Validation of Proposed Go-Around Criteria Under Various Environmental Conditions
}

\author{
Peter M.T. Zaal* \\ San Jose State University \\ NASA Ames Research Center \\ Moffett Field, CA \\ Jeffery A. Schroeder ${ }^{\ddagger}$ \\ Federal Aviation Administration \\ Moffett Field, CA
}

\author{
Angela M. Campbell ${ }^{\dagger}$ \\ Federal Aviation Administration \\ Atlantic City, NJ \\ Somil R. Shah ${ }^{\S}$ \\ Federal Aviation Administration \\ Atlantic City, NJ
}

This paper evaluates the effects of environmental conditions on touchdown performance under varying approach states and validates proposed go-around criteria developed using data from a previously conducted study under these various environmental conditions. An experiment was conducted using Boeing 737-800 and Airbus A330-200 Level D full-flight simulators in which 24 pilots flew multiple approaches under different approach conditions and environmental variables. Pilots were instructed to always land the aircraft, even from conditions considered to be an unstable approach. Various touchdown performance metrics were analyzed. In addition, pilots' perceptions of risk under the various unstable approach conditions and resulting landings were assessed. The results of the study revealed that wind speed/direction and visibility had a stronger effect on touchdown performance than the approach parameters. Specifically, wind had a highly significant effect on longitudinal and lateral touchdown point, as well as a significant effect on sinkrate at touchdown. Wind and visibility, along with localizer deviation, also had a strong effect on pilots' perception of risk and workload ratings. Furthermore, the study confirmed that touchdown performance was similar among the runs with a 300-ft and 500-ft starting gate, as was found in the previously conducted experiment. These results support the previous finding that lowering the go-around decision gate to $300 \mathrm{ft}$ might be acceptable, but suggest that certain environmental conditions might warrant altered thresholds of the proposed go-around criteria at this gate. Finally, the findings of this experiment highlight the importance of environmental factors in the assessment of risk of unwanted outcomes on approach and landing.

\section{Nomenclature}

$\begin{array}{llll}h_{g a} & \text { go-around altitude, ft } & \text { HITL } & \text { human in the loop } \\ \dot{h}_{t d} & \text { sinkrate at touchdown, ft/s } & \text { ILS } & \text { instrument landing system } \\ n_{r} & \text { percentage of runs with idle thrust, } \% & \text { LOC } & \text { localizer } \\ V_{r e f} & \text { reference speed, kt } & \text { PAPI } & \text { precision approach path indicator } \\ x_{50} & \text { runway distance left at } 50 \mathrm{kts}, \mathrm{ft} & \text { PF } & \text { pilot flying } \\ x_{t d} & \text { longitudinal touchdown point, ft } & \text { PFD } & \text { primary flight display } \\ y_{t d} & \text { lateral touchdown point, ft } & \text { PM } & \text { pilot monitoring } \\ & & \text { RCC } & \text { runway condition code } \\ \text { Abbreviations } & \text { REML } & \text { restricted maximum likelihood } \\ \text { CAVU } & \text { ceiling and visibility unlimited } & \text { RWY } & \text { runway } \\ \text { FAA } & \text { Federal Aviation Administration } & \text { SFO } & \text { San Francisco International Airport } \\ \text { GS } & \text { glideslope } & \text { TAWS } & \text { terrain avoidance warning system } \\ & & \text { VMC } & \text { visual meteorological conditions }\end{array}$

*Research Engineer, Human Systems Integration Division, Moffett Field, CA, 94035; peter.m.t.zaal@ nasa.gov. Senior Member.

$\dagger$ †erospace Engineer, William J. Hughes Technical Center, Atlantic City International Airport, NJ, 08405; angela.campbell@faa.gov. Member.

$\ddagger$ Chief Scientific and Technical Advisor for Flight Simulation Systems, Moffett Field, CA, 94035; jeffery.schroeder@ faa.gov. Associate Fellow.

$\S$ Aerospace Engineer, William J. Hughes Technical Center, Atlantic City International Airport, NJ, 08405; somil.shah@ faa.gov. Member.

The findings and conclusions in this paper are those of the authors and do not necessarily represent the views of the FAA. 


\section{Introduction}

This paper extends a previous study on the development of simplified, universal go-around criteria by further exploring the effects of environmental parameters on touchdown performance and go-around decision-making. ${ }^{1}$ The definition of stabilized approach criteria for transport category aircraft has fallen under scrutiny due to low compliance rates with established policies. Most airlines have defined stabilized approach criteria at specified gates. ${ }^{2}$ Typically, airline procedures state that if the pilot determines the approach is unstable, he or she should perform a go-around. However, the collective industry performance of complying with go-around policies is extremely poor, with only about $3 \%$ of unstable approaches resulting in a go-around. ${ }^{3}$

Studies by industry safety groups have suggested that the go-around noncompliance rate could be a significant safety hazard given that approach and landing are the most common phases of flight for aviation accidents, accounting annually for approximately $65 \%$ of all accidents. ${ }^{4}$ A Flight Safety Foundation study of 16 years of runway excursions found that $83 \%$ of accidents could have been avoided by a decision to go around; thus, $54 \%$ of all accidents could potentially be prevented by going around. ${ }^{5}$ Evidently, improving the go-around compliance rate holds significant potential in reducing approach and landing accidents.

Several organizations have investigated the root causes of go-around noncompliance and made recommendations for improving compliance rates. ${ }^{6}$ One of the biggest causes of noncompliance is that pilots believe the current stabilized approach criteria are too complex and restrictive for the operational environment. Recently, several airlines and safety organizations have established revised stabilized approach criteria based on their approach and landing risk assessments. One example of such revised criteria are guidelines suggesting that the go-around decision height can be lowered to as much as $300 \mathrm{ft}$ above ground level, compared to 500 or 1,000 ft used by most airlines today. ${ }^{5}$

A human-in-the-loop (HITL) simulation experiment was conducted during the fall of 2017 to validate some of the recommendations for revised criteria and determine whether it is feasible to develop universal, simplified stabilized approach or go-around criteria. ${ }^{1}$ The experiment investigated the likelihood of an abnormal landing under various approach states from 100-, 300-, and 500-ft gates, and assessed pilots' perception of landing risk of these approach states by removing the go-around decision-making process. A key finding was that

Table 1. Proposed go-around criteria.

\begin{tabular}{lll}
\hline \hline & Parameter & Threshold \\
\hline 1 & Gate Height & $300 \mathrm{ft}$ \\
2 & Airspeed & Within 0/+10 of target \\
3 & Glideslope Deviation & Less than 1 dot \\
4 & Localizer Deviation & Less than 1 dot \\
5 & Rate of Descent & No TAWS activation \\
\hline \hline
\end{tabular}

touchdown performance was similar among the runs with a $300-\mathrm{ft}$ and $500-\mathrm{ft}$ starting gate despite the different approach states, supporting the lowering of the go-around decision height to $300 \mathrm{ft}$. Based on these results, a set of simplified go-around criteria was proposed, as shown in Table 1. However, a key limitation of these proposed criteria is that they were formulated using experimental data from one environmental condition: a 10-knot tailwind and ceiling and visibility unlimited (CAVU).

This paper examines the validity of the findings of the previous study and the applicability of the proposed criteria in Table 1 under several wind and visibility conditions. More specifically, it addresses two questions: (1) is a lower go-around decision height of $300 \mathrm{ft}$ still feasible under typical environmental variations? and (2) do environmental variations change the criterion boundaries for the remaining approach parameters at the $300-\mathrm{ft}$ gate? The paper adds to the literature as follows. First, it investigates the likelihood of an abnormal landing under various approach states and environmental conditions. Second, it assesses pilots' perception of landing risk from these approach states and environmental conditions by taking out the go-around decision-making process. Third, it includes results from both narrow-body and wide-body aircraft, and from Boeing and Airbus types, by using two level-D full flight simulators. Finally, a sufficiently large pilot pool added statistical reliability to the results.

The paper is structured as follows: an overview of the approach and landing task is provided in Section II, the experiment setup is described in Section III, experiment results are provided in Section IV, the results are discussed in Section V, and various conclusions are made in Section VI.

\section{Approach and Landing Task}

The basic premise of the experiment was to correlate touchdown performance (dependent measures) with various approach states and environmental conditions (independent variables) by requiring pilots to land the aircraft in a defined touchdown zone under a variety of initial-approach conditions (starting conditions) in Boeing 737-800 and Airbus A330-200 Level D full-flight simulators. Test subjects were required to always land the aircraft (no go-arounds were allowed), even from conditions considered to be unstable by their airline and regardless of whether they person- 


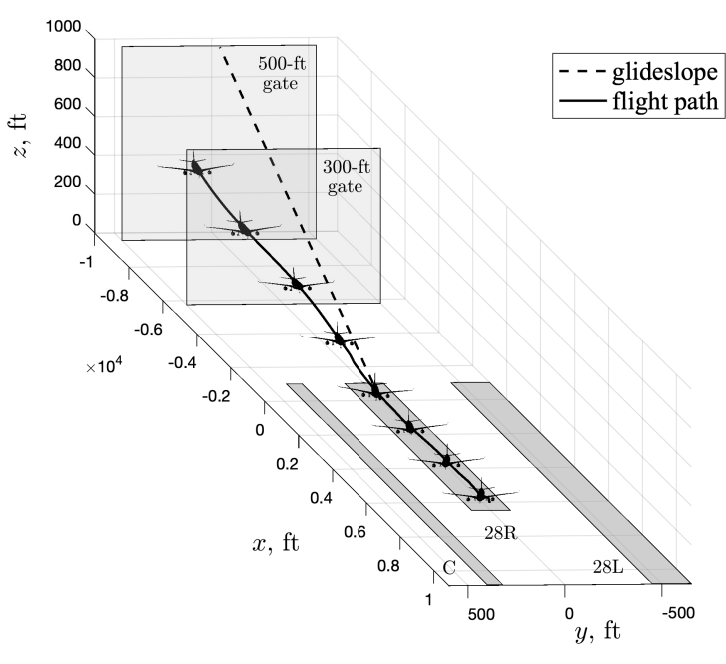

Figure 1. Mean B737 trajectory with lateral instability.
Task: approach and landing to SFO RWY 28R (shortened to 7,500 ft)

Initial Condition: trim condition and location with respect to GS and LOC vary each run

Configuration: gear down, flaps full landing, speedbrakes retracted

Weight: maximum landing weight

Ceiling/Visibility: CAVU or 3-mile visibility (depending on run)

Wind: $190 / 20,10 / 20$, or 100/10 (depending on run)

Turbulence: moderate Gusts: none

Runway: wet, medium braking action, $\operatorname{RCC~3/3/3~}$

Procedure:

1. Recover from a possible unstable approach to SFO RWY 28R (full recovery might not be possible)

2. Continue to land on RWY $28 \mathrm{R}$

3. Flare and touchdown meeting, or as close to, desired touchdown criteria as possible

4. Apply thrust reversers and full manual braking

5. Task evaluation ends after the aircraft is fully stopped on the runway

Desired Performance:

1. Longitudinal touchdown: $1,000-2,000 \mathrm{ft}$ from threshold

2. Lateral touchdown: centerline between main wing gear

3. Sinkrate at touchdown: $\leq 6 \mathrm{ft} / \mathrm{s}$

4. Bring the aircraft to a full stop as quickly as possible

Figure 2. Experiment flight card.

ally felt that a go-around should be conducted. The reason for this decision in the experiment design was to remove the go-around decision-making process and to get an objective assessment of the likelihood of an abnormal landing under various approach states. The expectation was that, under certain approach states, pilots would do the following: (a) land outside the specified touchdown zone; (b) have excessive speed at touchdown; or (c) have excessive sinkrate at touchdown. Under these conditions, the risk of an accident or incident would be elevated in reality. Using results from this experiment, a determination can be made regarding the limits for which a pilot can land safely with an acceptable risk. These approach-parameter limits provide additional data to help with the development and validation of possible universal and simplified go-around criteria for transport category aircraft (Table 1).

All approaches and landings were flown to an artificially shortened version of runway (RWY) 28R at San Francisco International Airport (SFO). The runway in the simulation was 7,500 ft long (11,870 ft in reality), $200 \mathrm{ft}$ wide, and had a displaced threshold. The mean trajectory of one of the experimental conditions is provided in Fig. 1, along with the location of runways $28 \mathrm{~L}$ and $28 \mathrm{R}$, and taxiway C. All trials were flown with moderate turbulence onto a wet runway with medium braking action, at the maximum landing weight, and without any automation. These challenging environmental, runway, and aircraft parameters were selected to increase the difficulty of recovering from an unstable approach and landing the aircraft. The assumption was that go-around criteria developed under these extreme conditions would be conservative and applicable to more favorable conditions.

As the aircraft was always below $1,000 \mathrm{ft}$ for the experiment, it was always in its landing configuration (gear down and flaps at the correct setting for the given aircraft type). Pilots were able to use localizer and glideslope error indicators on the primary flight display (PFD) and the precision approach path indicator (PAPI) at RWY 28R at their own discretion. In addition, in order to time the flare of the aircraft, standard radio-altitude call-outs began at a main landing gear height of $50 \mathrm{ft}$ and repeated in decrements of $10 \mathrm{ft}$ until touchdown. Pilots were instructed to use maximum manual braking in order to bring the aircraft to a full stop on the runway as quickly as possible.

Touchdown performance metrics were developed using subject-matter-expert input and published guidance. The selected metrics were representative of what would be considered a routine landing in normal operations. One metric of interest was the touchdown point. Landing too close to the threshold increases the risk of an undershoot, and landing too far down the runway increases the risk of a runway overrun. Additionally, large deviations from the centerline 


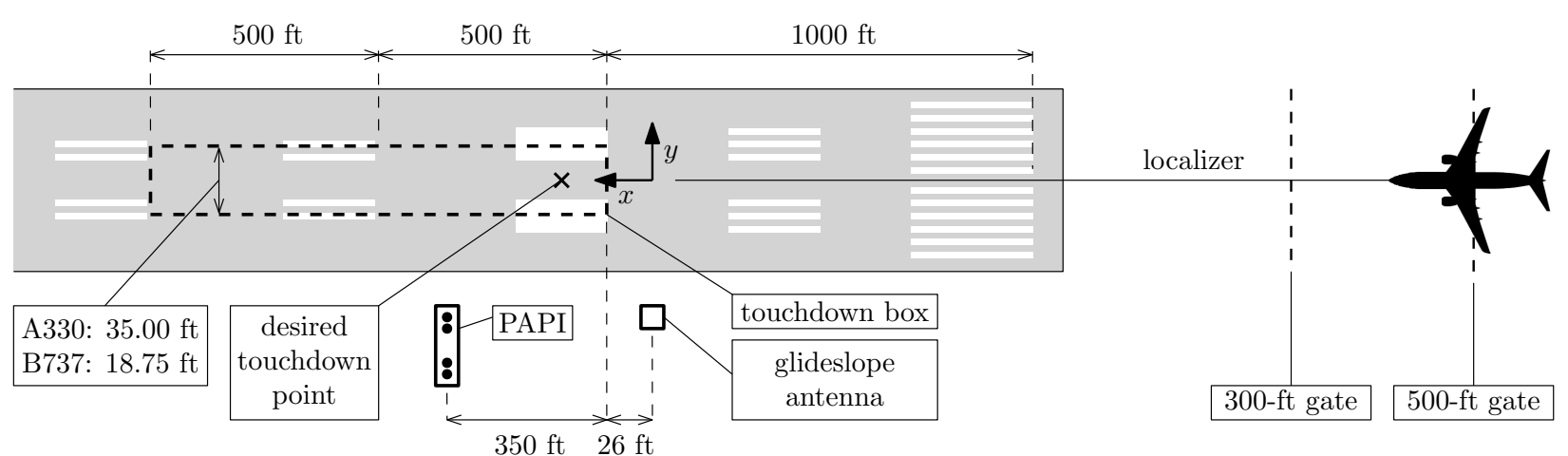

Figure 3. Touchdown zone definition.

increase the risk of a runway veer-off. Based on these considerations, a touchdown box was created to bound the acceptable area for the aircraft to touchdown. The touchdown box began at 1,000 ft past the threshold and ended at $2,000 \mathrm{ft}$. The width of the box was equal to the distance between the main gear of the aircraft ( $35.00 \mathrm{ft}$ and $18.75 \mathrm{ft}$ for the A330-200 and B737-800, respectively). The touchdown box is illustrated in Fig. 3. The other performance metric of interest was the rate of descent at touchdown. An unstable approach with high energy could potentially lead to a hard landing. A threshold of $6 \mathrm{ft} / \mathrm{s}$ was used for the touchdown criteria.

The approaches and landings were flown by crews comprised of a captain and a first officer from the same airline. Both pilots alternated as the pilot flying (PF) and pilot monitoring (PM) in between sessions. This allowed for objective data and subjective evaluations from both perspectives. The flight card for the approach and landing task is provided in Fig. 2.

\section{Experiment Setup}

\section{III.A. Independent Variables}

The initial approach and environmental parameters were the independent variables of the experiment: gate height (300 or $500 \mathrm{ft}$ ), glideslope deviation ( 0 or $1 \mathrm{dot})$, localizer deviation $(0$ or $1 \mathrm{dot})$, reference speed deviation $(+5,+10$, or $+15 \mathrm{kts}$ ), wind (left crosswind at $20 \mathrm{kts}$, right crosswind at $20 \mathrm{kts}$, or tailwind at $10 \mathrm{kts}$ ), and visibility (unlimited or $3 \mathrm{sm}$ ). These independent variables and their levels were selected based on the results of the first simulation experiment conducted in $2017^{1}$ and are the main parameters that would be used in the refinement of go-around criteria. Other approach parameters, such as the rate of descent, power setting, and maximum bank angle, were not included as independent variables in the current study. Nonetheless, they were tracked to determine whether they have any significant influence on touchdown performance. The independent variables are summarized in Table 2.

Table 2. Independent variable settings.

\begin{tabular}{cccccc}
\hline \hline $\begin{array}{c}\text { Gate Height } \\
\mathrm{ft}\end{array}$ & $\begin{array}{c}V_{\text {ref }} \text { Deviation } \\
\text { kts }\end{array}$ & $\begin{array}{c}\text { GS Deviation } \\
\text { dot }\end{array}$ & $\begin{array}{c}\text { LOC Deviation } \\
\text { dot }\end{array}$ & Wind & \multicolumn{2}{c}{ Visibility } \\
kts & sm \\
\hline 300 & $+5 /+10 /+15$ & $0.0 / 1.0$ & $0.0 / 1.0$ & left 20/right 20/tail 10 & $\infty / 3.0$ \\
500 & $+5 /+10 /+15$ & $0.0 / 1.0$ & $0.0 / 1.0$ & left 20/right 20/tail 10 & $\infty / 3.0$ \\
\hline \hline
\end{tabular}

To reduce the size of the final test matrix, only localizer deviations to the right of the runway were considered, assuming that deviations from the left and right would have similar but opposite effects. This was also more realistic given the parallel runway to the left (28L) at SFO. In addition, only deviations above the glideslope were considered, as these are more difficult to compensate for than deviations below the glideslope. Furthermore, only speed deviations above the reference speed $V_{\text {ref }}$ were tested; speed deviations below increase the risk of stall and almost always warrant a go-around.

A test matrix was generated using the custom design of experiments feature in $\mathrm{JMP}^{\circledR 7}$ to determine the number of runs and scenarios that each pilot would need to fly during the experiment. A full-factorial design was not used, because the allotted time in the simulator would not allow for repeated conditions. The custom design-of-experiments option allowed replicates of the corners of the design while maintaining an experiment power of one for main effects 
and first-order interactions. The test matrix, provided in the appendix, had 30 different conditions and a total of 42 runs with replicates included. The final test matrix had 46 runs, including four training runs.

\section{III.B. Apparatus}

The experiment was carried out using the B737-800 and A330-200 Level D full-flight simulators located at the Federal Aviation Administration (FAA) Mike Monroney Aeronautical Center in Oklahoma City (Figs. 4 and 5). The two aircraft types tested provided the ability to compare results among both narrow-body and wide-body aircraft, and among the Boeing and Airbus makes. Using this approach allowed for a possible broadening of the criteria.

Both simulators were from the same manufacturer and used in their standard configurations. Differences between simulators existed because of the different years of initial operation and the different aircraft types simulated. Care was taken to make all basic aircraft and environmental settings as similar as possible between simulators. For example, cockpit radio-altitude and warning call-outs, turbulence intensity, and runway and radio-navigation-aid geometries were equalized to provide pilots with similar basic cues across simulators. Motion cues were provided in each simulator using the standard motion logic settings. The B737 simulator has a hydraulic hexapod motion system, and the A330 simulator uses an electric hexapod motion system.

All approaches and landings were flown without any automation engaged. Autopilots, autothrottles, autobrakes, and flight directors were turned off. The PFD depicted conventional localizer and glideslope error indicators. Fig. 6 shows the PFD in the B737-800 simulator, with the corresponding out-the-window visual provided in Fig. 7. Note that in this condition, the aircraft is approximately lined up with the taxiway to the right of RWY 28R.

Pilots used tablets (touchscreen laptop computers) to fill out a questionnaire after each approach and landing in the simulator. These tablets were mounted on the left and right sides of the simulator cabs for the captain and first officer, respectively, for easy access.

\section{III.C. Participants}

Six crews comprised of a captain and a first officer from the same airline participated in each simulator, giving a total of 12 crews or 24 pilots for the entire experiment. Crews from three different airlines participated. Most pilots were very experienced with ratings on many aircraft types. All A330 and B737 pilots were current and qualified as captain or first officer in a Part 121 air carrier. All pilots gave written consent for their participation and received compensation.

\section{III.D. Procedures}

Each crew was scheduled for two consecutive days, with each day having a separate focus. This paper reports on the results of the experiment on day one. Pilots were provided a briefing document and flight card (Fig. 2) prior to the start of the experiment. On the first day, crews received an extensive pre-briefing, explaining the schedule, task, conditions, and procedures expected during the experiment. Crews were told that the experiment investigated the effects of different approach parameters on landing performance but were given no specifics regarding the true nature of the experiment. Crews were informed that they would fly 92 approach and landing scenarios with different initial approach and environmental conditions, and that the conditions would be presented randomly. After the briefing, pilots provided their informed consent and filled out a pre-simulation questionnaire. This questionnaire gathered general demographic data and information on their airline's current stable approach criteria in visual meteorological

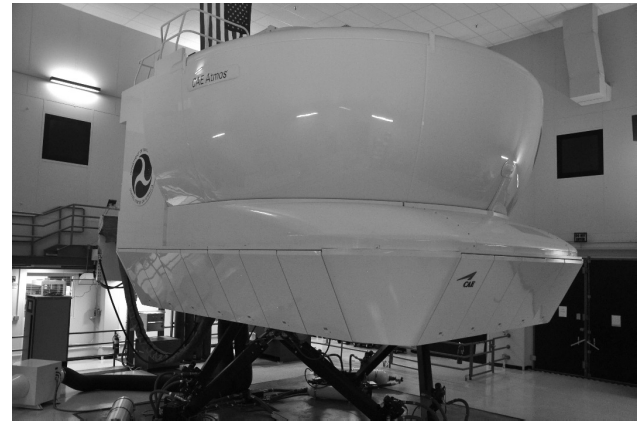

Figure 4. B737-800 simulator.

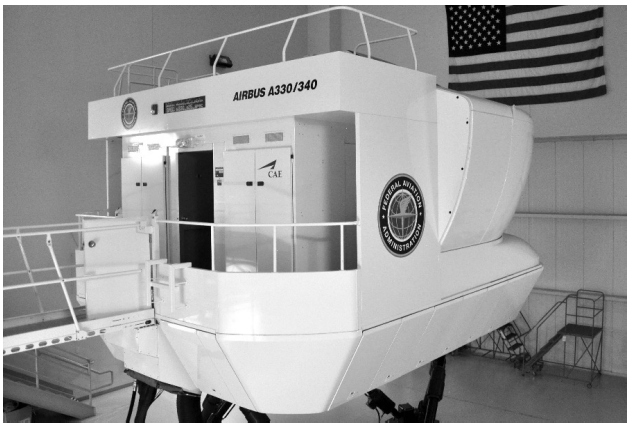

Figure 5. A330-200 simulator. 


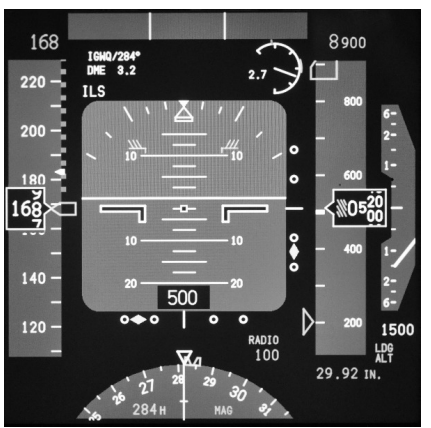

Figure 6. B737-800 PFD.

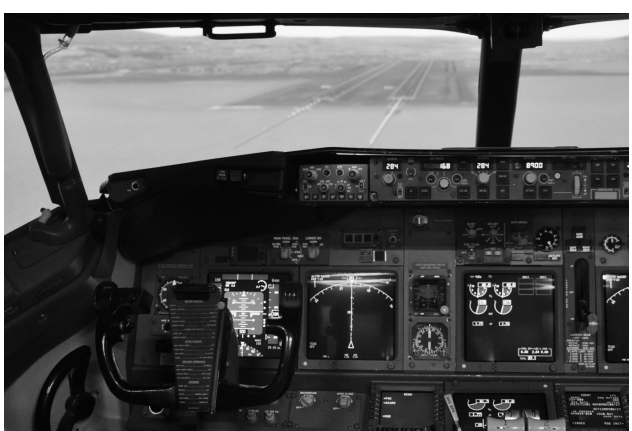

Figure 7. Out-the-window view.

conditions (VMC), as well as asked about their satisfaction with those criteria. The experiment began following a simulator safety briefing.

Each crew flew 92 scenarios, divided among four 1-hour simulator sessions. Pilots received breaks outside of the simulator cab between sessions. The length of the breaks was at pilots' own discretion, but was typically 15-30 minutes. Pilots were allowed to take additional breaks at any time during a session if desired. Over the course of the first day of experimentation, each pilot flew all 30 conditions in the test matrix (Table 7). Some of the conditions were performed twice. The runs were randomized for each pilot, and pilots rotated between the PF and the PM in between each session. The first four runs of the first session were training runs with the various environmental conditions.

Each run started with the aircraft either at the $300-\mathrm{ft}$ gate, or the $500-\mathrm{ft}$ gate. The PF flew each approach and landed the aircraft during every run of a session. The initial approach and environmental parameters were called out to the pilots by the experimenter before the start of each run to make sure pilots were completely aware of the situation. After pilots confirmed they were ready, the experimenter counted down to the initiation of the run. Pilots were also instructed to press the autopilot disconnect button to indicate the moment at which they normally would have performed a go-around. The PF was asked to meet the touchdown criteria as closely as possible and then to use maximum manual braking and full reverse thrust to bring the aircraft to a complete stop on the runway. The pilot monitoring was allowed to provide call-outs to assist the PF, as per their airline policy or personal preference. After the aircraft had come to a complete stop, the simulator was re-positioned for the next run, and the pilots answered their post-run questionnaires on the tablet computers (see Section III.E).

After completing all simulator runs, pilots filled out a post-simulation questionnaire. This questionnaire asked about the pilots' preferred stable approach criteria based on their experiences during the experiment and about which factors influenced their decision to go around the strongest. Finally, each crew received a debriefing providing more details about the true nature of the experiment.

\section{III.E. Dependent Measures}

Three main objective dependent measures specifying landing performance were recorded and analyzed: longitudinal and lateral touchdown location $\left(x_{t d}\right.$ and $\left.y_{t d}\right)$ and the sinkrate at touchdown $\left(\dot{h}_{t d}\right)$. These measures related directly to the landing performance criteria the pilots were required to meet (Fig. 2). The touchdown point was defined as where the center of the main landing gear touched the runway with respect to the longitudinal location of the glideslope antenna and the centerline of the runway (Fig. 3). When multiple touchdowns were recorded (i.e., when a bounced landing occurred), the maximum longitudinal distance and maximum sinkrate out of all touchdowns were used. The lateral distance always corresponded with the maximum longitudinal distance. For most cases, this meant that for a bounced landing, the sinkrate used belonged to the first touchdown, and the longitudinal and lateral touchdown locations used belonged to the last touchdown. Along with the primary objective dependent measures, the runway remaining when the aircraft slowed to $50 \mathrm{kts}, x_{50}$, was captured because this is a good indication of the risk of a runway overrun. Finally, the go-around altitude, $h_{g a}$, was recorded at the time of the autopilot-disconnect button press.

Seven subjective dependent measures were recorded using a questionnaire administered on a tablet at the conclusion of each run. Pilots first rated their workload, fatigue, and perceived risk of the previous landing (in that order) on a 20-point scale, by moving a slider bar with their finger. Only the ends and midpoints of the slider bars were marked with "low," "average," and "high." Next, pilots were asked if they pressed the autopilot disconnect button indicating a go-around should have been performed. If they responded with a yes, the pilots indicated which factors influenced 
the go-around decision by selecting from a list that included the following options: slow, fast, low descent rate, high descent rate, below glideslope, above glideslope, localizer deviation, power setting, bank angle, wind, visibility, turbulence, runway length, and runway condition. It was possible to select multiple factors for each run. Finally, the last two questions asked the pilot if his/her decision to go around would have been different if the runway was longer or if the braking action was better. Note: both the PF and the PM filled out the post-run questionnaire, resulting in two sets of subjective data for each run.

\section{Results}

At the completion of the HITL simulation experiment, data were collected from 1,008 approaches and landings from 24 pilots in total. The analysis focused on gathering statistical information on the aggregate data set. Individual pilot or airline performance was not evaluated. Both the objective performance data and subjective tablet questionnaire responses were analyzed to validate the findings of the first experiment conducted in 2017 as well as to determine the influence of the environmental variables. The data were compiled and analyzed using MATLAB ${ }^{\circledR 8}$ and JMP ${ }^{\circledR} .7$

Results presented below are aggregate data from both simulators. Boxplots present medians and first and third quartiles of the aggregate data. The ends of the whiskers represent the lowest data point still within 1.5 times the interquartile range of the first quartile, and the highest data point still within 1.5 times the interquartile range of the third quartile. Data points outside of the whiskers are outliers and presented by gray $\mathrm{x}$-symbols. The means of the data are depicted by black x-symbols. Dashed black lines indicate the touchdown performance criteria and gray shaded areas indicate desired performance, if applicable.

\section{IV.A. Performance Data}

The primary goal of the objective data analysis was to determine the effect of the approach and environmental parameters on touchdown performance. Boxplots of the touchdown performance metrics are depicted in Figs. 8, 9, and 10. Data are grouped by gate height. Each figure contains four plots: one for each of the remaining independent variables (reference speed deviation, localizer and glideslope deviation, wind condition, and visibility).

To determine if significant differences were introduced in the touchdown performance dependent measures by the experiment independent variables, a mixed-model analysis was performed. A mixed model is a statistical model that contains both fixed and random effects. Fixed effects are those that are of primary interest to the study. Random effects have many levels which influence the study results, but are not of primary interest to the research. ${ }^{9}$ In this study, the fixed effects used in the model were the approach variables and the environmental conditions. The random effects were subject-related effects. A mixed-model analysis was chosen because it does not have the traditional analysis-of-variance method restrictions on test design and balance of data. ${ }^{10}$

Through the fit model platform in JMP ${ }^{\circledR}$, a mixed model was created using the Restricted Maximum Likelihood (REML) estimation method. ${ }^{11}$ Localizer deviation, glideslope deviation, reference speed deviation, rate of descent, and the environmental conditions (visibility and wind speed/direction) were set as the fixed effects, and pilot ID was set as the random effect. The touchdown performance measures (longitudinal touchdown point, lateral touchdown point, rate of descent at touchdown, and runway remaining at $50 \mathrm{kts}$ ) were specified as the dependent variables. Using these inputs, JMP ${ }^{\circledR}$ produced the model parameter estimates, REML variance component estimates, and fixed effect tests.

A summary of the mixed-model analysis on the touchdown dependent measures is provided in Table 3 . The table provides the degrees of freedom $d f, F$, and $p$-values for the model. The table cells are shaded to indicate whether the independent variables introduced highly significant, significant, or no significant differences in the dependent measures. Differences in longitudinal touchdown point introduced by wind direction and visibility were highly significant. Fig. 8 indicates that the touchdown point was typically further down the runway if a tailwind was present and pilots tended to land closer to the threshold in low visibility conditions. In addition, the gate height introduced statistically significant differences in the longitudinal touchdown point; however, the difference in mean touchdown point for the two gate heights was less than $50 \mathrm{ft}$. Target airspeed, glideslope, and localizer deviations did not introduce significant differences in the longitudinal touchdown point.

The wind direction introduced highly significant differences in the lateral touchdown point. Fig. 9 shows that with a right crosswind, pilots frequently landed to the left of the centerline. With a left crosswind, pilots tended to land to the right of the centerline. Pilots landed closer to the centerline when a tailwind was present. None of the other independent variables introduced significant differences in the lateral touchdown point. 

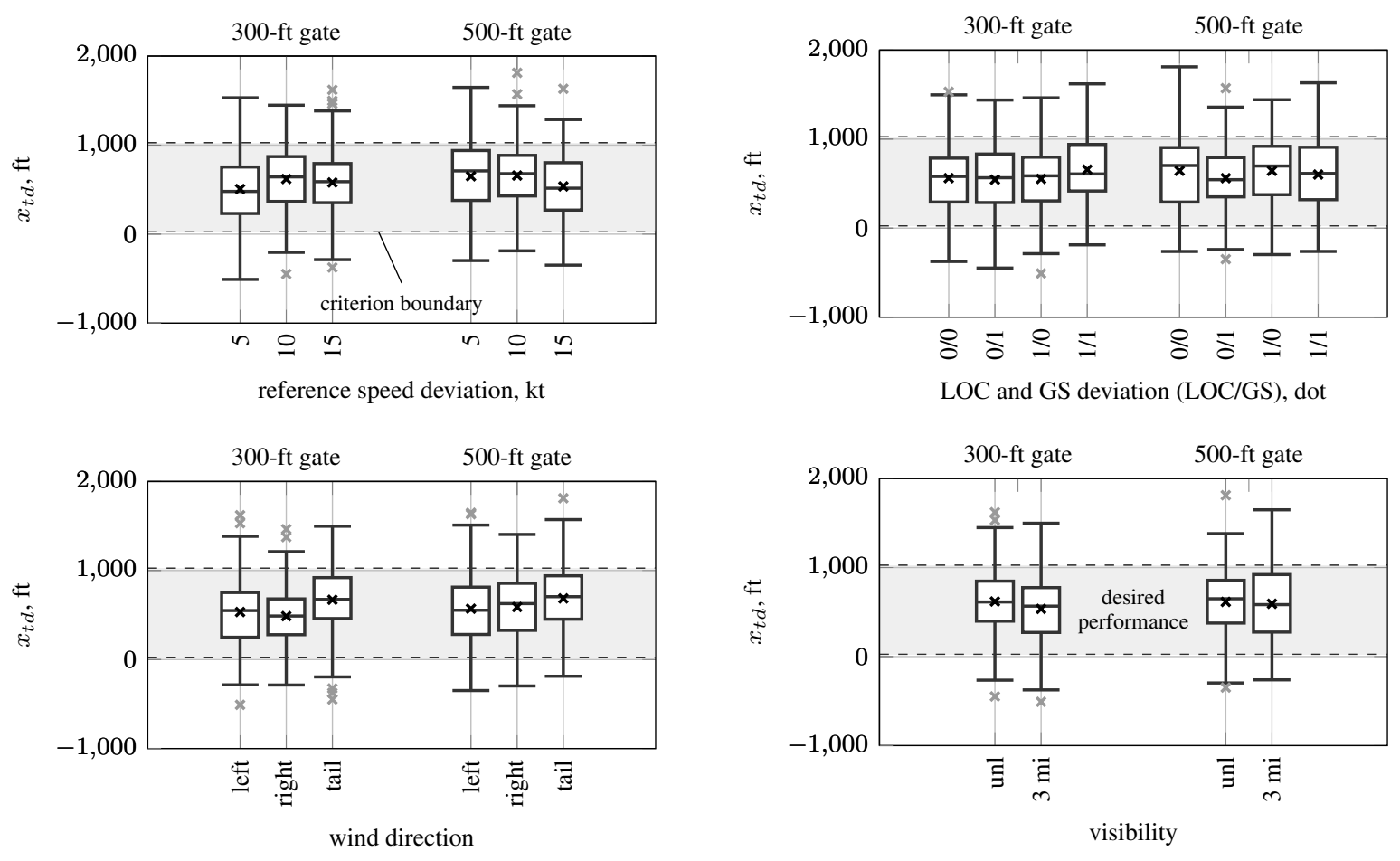

Figure 8. Effects of the independent variables on longitudinal touchdown point.
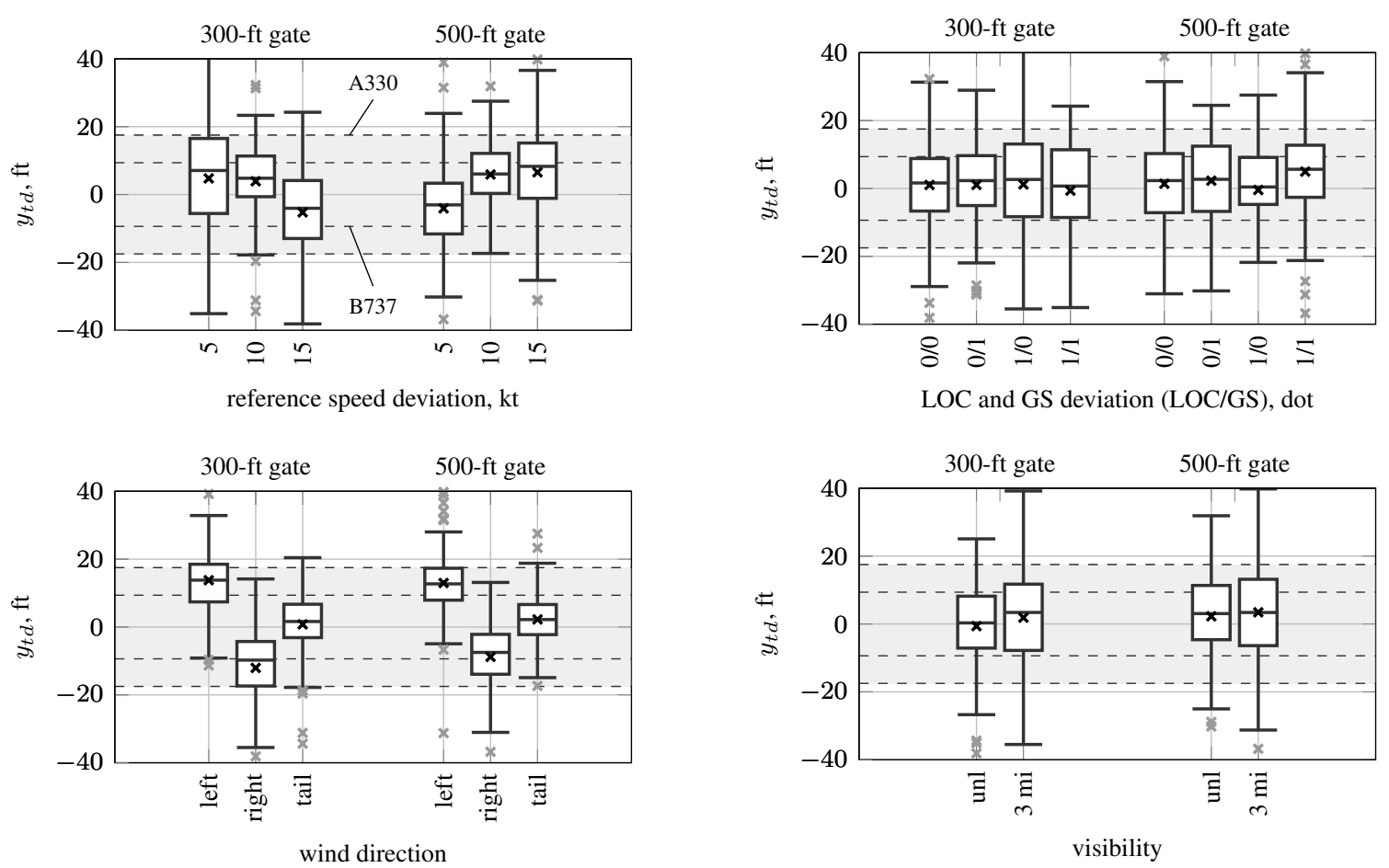

Figure 9. Effects of the independent variables on lateral touchdown point. 



Figure 10. Effects of the independent variables on sinkrate at touchdown.
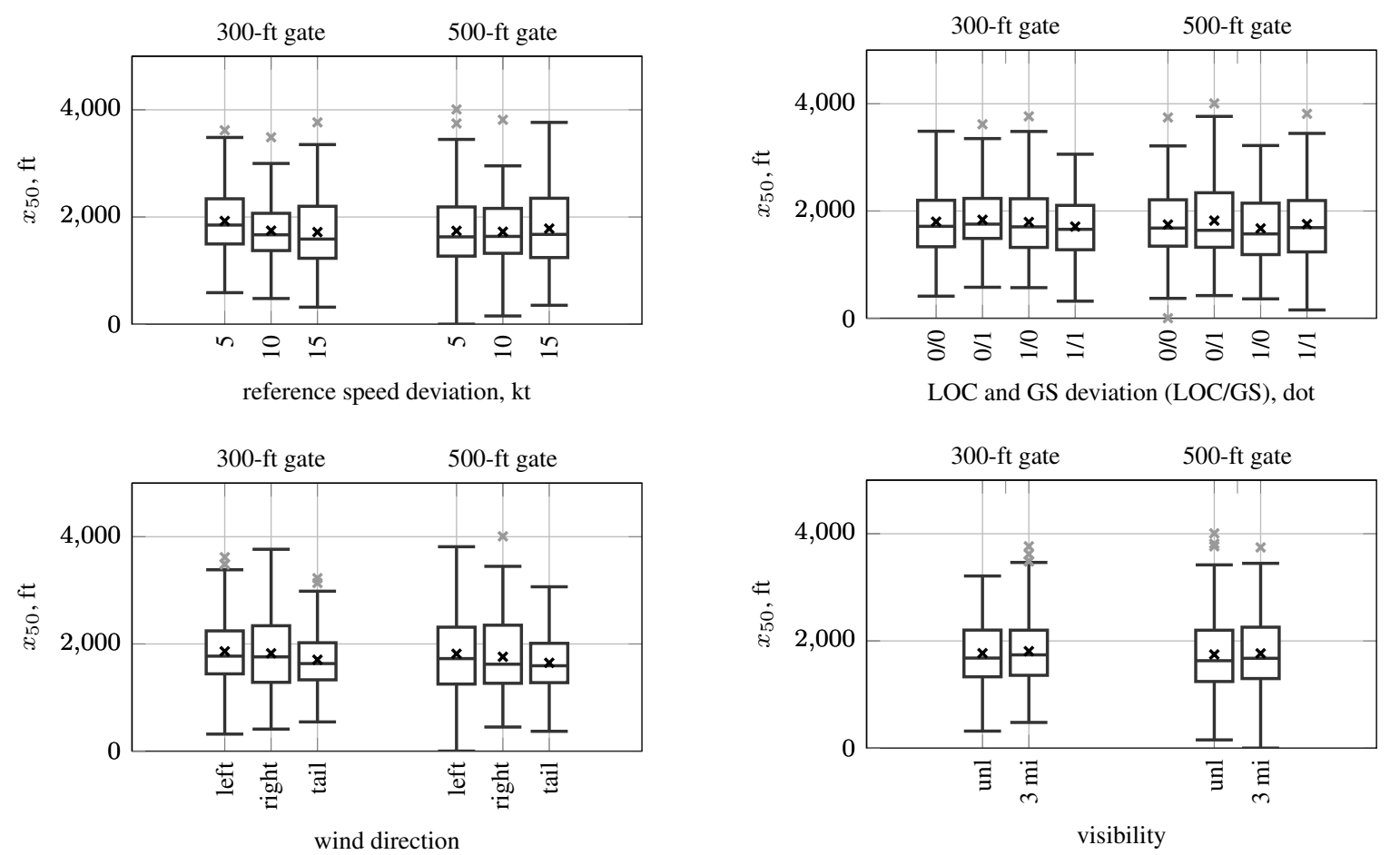

Figure 11. Effects of the independent variables on runway distance remaining at $50 \mathrm{kts}$. 
Table 3. Summary of main statistical test results for objective touchdown performance data.

\begin{tabular}{|c|c|c|c|c|c|c|c|c|c|}
\hline \multirow[t]{3}{*}{ Independent Variables } & \multirow[b]{3}{*}{$d f$} & \multicolumn{8}{|c|}{ Dependent Measures } \\
\hline & & \multicolumn{2}{|c|}{$x_{t d}$} & \multicolumn{2}{|c|}{$y_{t d}$} & \multicolumn{2}{|c|}{$\dot{h}_{t d}$} & \multicolumn{2}{|c|}{$x_{50}$} \\
\hline & & $F$ & $p$ & $F$ & $p$ & $F$ & $p$ & $F$ & $p$ \\
\hline Gate Height & 1,976 & 4.3424 & 0.0374 & 3.4316 & 0.0643 & 0.0078 & 0.9298 & 3.4948 & 0.0619 \\
\hline$V_{\text {ref }}$ Deviation & 2,976 & 0.4558 & 0.6341 & 0.7290 & 0.4827 & 2.9205 & 0.0544 & 3.7178 & 0.0246 \\
\hline Glideslope Deviation & 1,976 & 1.3364 & 0.2480 & 0.5306 & 0.4665 & 0.2209 & 0.6385 & 2.0484 & 0.1527 \\
\hline Localizer Deviation & 1,976 & 1.4713 & 0.2254 & 0.0219 & 0.8824 & 0.0691 & 0.7928 & 5.4886 & 0.0193 \\
\hline Wind & 2,976 & 17.4069 & $<.0001$ & 308.519 & $<.0001$ & 4.3008 & 0.0138 & 12.2275 & $<.0001$ \\
\hline Visibility & 1,976 & 6.9911 & 0.0083 & 0.1111 & 0.7390 & 0.4111 & 0.5216 & 0.7581 & 0.3841 \\
\hline
\end{tabular}

$$
\begin{array}{ll}
=\quad \text { highly significant }(p<0.01) \\
=\quad \text { significant }(0.01 \leq p<0.05) \\
=\quad \text { not significant }(p \geq 0.05)
\end{array}
$$

Target airspeed deviations and wind direction introduced significant differences in the sinkrate at touchdown. Fig. 10 indicates that the sinkrate at touchdown was significantly higher for higher airspeed deviations. The touchdown sinkrate was also significantly higher in the conditions with a crosswind. Gate height, glideslope and localizer deviations, and visibility did not introduce significant differences in the sinkrate at touchdown.

The runway distance remaining at $50 \mathrm{kts}$ is depicted in Fig. 11. The mixed-model analysis showed that $V_{\text {ref }}$ deviations introduced significant differences in the runway distance remaining at $50 \mathrm{kts}$. Fig. 11 indicates that increased reference speed deviations decreased the runway distance left at $50 \mathrm{kts}$. Like the results of the previous experiment, this effect was mainly present for $V_{\text {ref }}$ deviations at the lower gate height. ${ }^{1}$ Table 3 indicates a highly significant difference in runway remaining at $50 \mathrm{kts}$ introduced by the wind direction. Fig. 11 indicates that the runway distance remaining at $50 \mathrm{kts}$ was lower in the tailwind conditions compared to the crosswind conditions. The mixed-model analysis also detected that a localizer deviation introduced a significant difference in runway distance remaining; however, the effect on the mean distance remaining was less than $60 \mathrm{ft}$.

Fig. 12 presents the percentage of runs with idle thrust in the approach. The percentage of runs with idle thrust was generally low, around 3\%. The percentage increased for increasing reference speed deviations at the 500-ft gate. In addition, pilots selected idle thrust during the approach more often in the tailwind condition compared to the crosswind conditions. In the previous experiment, pilots selected idle thrust in significantly more runs. This might have been due to the higher target airspeed deviations in this experiment.

Both the PF and the PM indicated when they normally would have gone around by pressing the autopilotdisconnect button. The go-around altitude, the altitude at the time of the autopilot-disconnect button press, is depicted in Fig. 13. As PF and PM responses were similar, data were collapsed across pilot roles. A mixed-model analysis was performed to evaluate the significance of the differences introduced by the experiment independent variables on the go-around altitude metric (Table 4). The mixed-model fixed effects were the experiment independent variables and the random effect was the pilot ID.

Fig. 13 shows that pilots indicated they would have gone around at a wide range of altitudes. The summarized mixed-model results in Table 4 show that the gate height and the localizer deviation had the strongest effect on goaround altitude. The mean go-around altitude for the runs that started at $300 \mathrm{ft}$ was $155 \mathrm{ft}$ and the mean go-around altitude for the 500-ft runs was $243 \mathrm{ft}$. The go-around altitude was higher for runs with a localizer deviation; that is, pilots indicated that they would have gone around sooner. In addition, the mixed-model analysis revealed a statistically significant difference in go-around altitude introduced by glideslope deviation; however the difference in the means between the groups was only $25 \mathrm{ft}$, which is unlikely to have operational significance. Furthermore, Fig. 13 indicates that pilots opted to go around sooner with a tailwind when the run started at $500 \mathrm{ft}$.

Fig. 13 also provides the percentages of go-arounds for each condition at the top of every plot. Pilots indicated that they would have gone around more often in the $V_{\text {ref }}+5$ and $V_{\text {ref }}+15$ conditions compared to the $V_{\text {ref }}+10$ condition. In addition, pilots indicated significantly more often they would have gone around with a localizer deviation. Pilots also pressed the autopilot-disconnect button more often in the crosswind conditions compared to the tailwind conditions. Finally, pilots indicated significantly more often that they would have gone around in the conditions with limited visibility compared to unlimited visibility. 

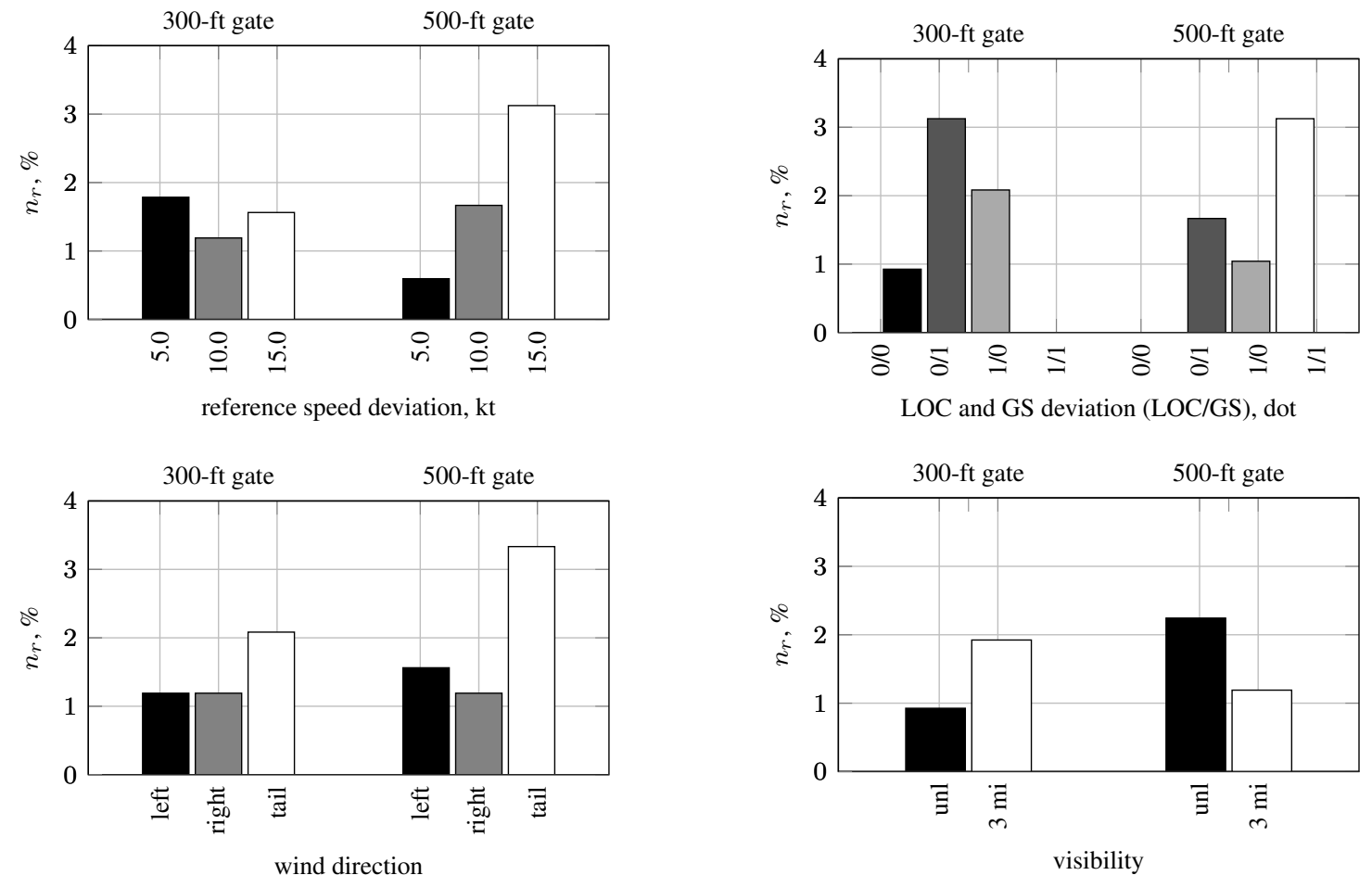

Figure 12. Effects of the independent variables on the percentage of runs with idle thrust in the approach.


Figure 13. Effects of the independent variables on go-around altitude (collapsed across PF and PM). 
Table 4. Summary of main statistical test results for go-around altitude.

\begin{tabular}{lrrr}
\hline Independent Variables & & \multicolumn{2}{c}{$h_{g a}$} \\
\cline { 3 - 4 } & $d f$ & \multicolumn{1}{c}{$F$} & \multicolumn{1}{c}{$p$} \\
\hline Gate Height & 1,386 & 68.2137 & $<.0001$ \\
$V_{\text {ref }}$ Deviation & 2,385 & 0.9598 & 0.3839 \\
Glideslope Deviation & 1,380 & 4.9193 & 0.0271 \\
Localizer Deviation & 1,386 & 24.8042 & $<.0001$ \\
Wind & 2,380 & 2.7674 & 0.0641 \\
Visibility & 1,384 & 0.8316 & 0.3624 \\
\hline \hline
\end{tabular}

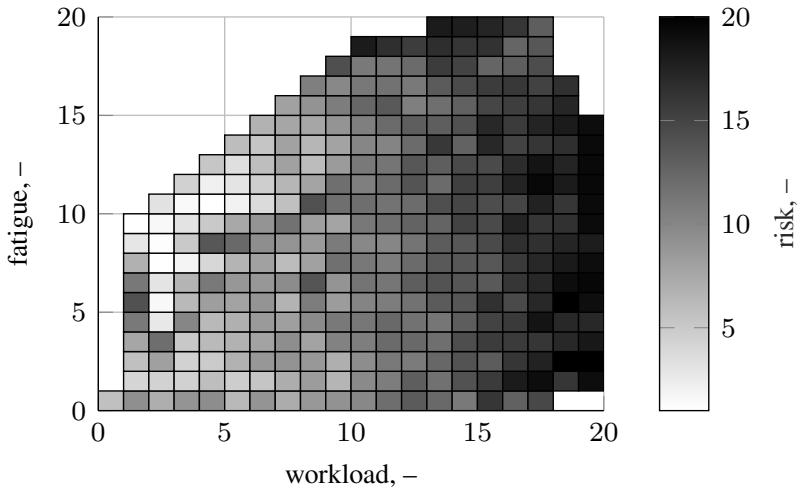

$$
\begin{array}{ll}
= & \text { highly significant }(p<0.01) \\
= & \text { significant }(0.01 \leq p<0.05) \\
= & \text { not significant }(p \geq 0.05)
\end{array}
$$

Figure 14. Risk perception vs. workload and fatigue (PF and PM data).

\section{IV.B. Subjective Data}

The combined questionnaire responses for the B737 and A330 simulators resulted in 2,016 sets of questionnaire data ( 84 from each pilot). These subjective questionnaire data were analyzed to better understand the pilots' landing risk assessment of flying the aircraft under the various approach and environmental parameters experienced in the simulation experiment. Analysis was also performed to determine which factors had the greatest influence on pilots' decision to land or conduct a go-around.

\section{IV.B.1. Pilot Perception of Workload, Fatigue, and Risk}

After each run, the tablet questionnaire first asked pilots to rate their fatigue, workload, and landing risk for the previous run. Fatigue, workload, and risk were rated on a scale between 0 and 20. A contour plot of risk evaluation for each run as a function of workload and fatigue is shown in Fig. 14. Some areas of the plot have no data (most notably a combination of low workload and high fatigue levels), as pilots did not rate any of the runs with certain combinations of fatigue and workload levels. The plot shows that the perception of landing risk increased with workload and fatigue. In addition, workload had a stronger effect on perceived landing risk than fatigue. This is in line with the previous experiment conducted in $2017 .^{1}$

In addition, workload, fatigue, and landing risk ratings were evaluated with regard to the pilot role (PF or PM) and the run number. A one-way analysis was performed using $\mathrm{JMP}^{\circledR}$ to determine the effect of pilot role on the tablet questionnaire ratings, and a simple bivariate analysis was performed to determine the effect of run number. ${ }^{12}$ From these analyses, it was found that workload ratings were primarily influenced by pilot role $(p<0.0001)$ and fatigue ratings by run number $(p<0.0001)$. Pilots flying experienced a higher workload, while fatigue increased with run number. Risk ratings were more influenced by pilot role $(p=0.0091)$ than run number $(p=0.1500)$. However, the pilots' perception of landing risk was primarily affected by the independent variables controlled in the simulation

Table 5. Summary of main statistical test results for workload and risk-rating data.

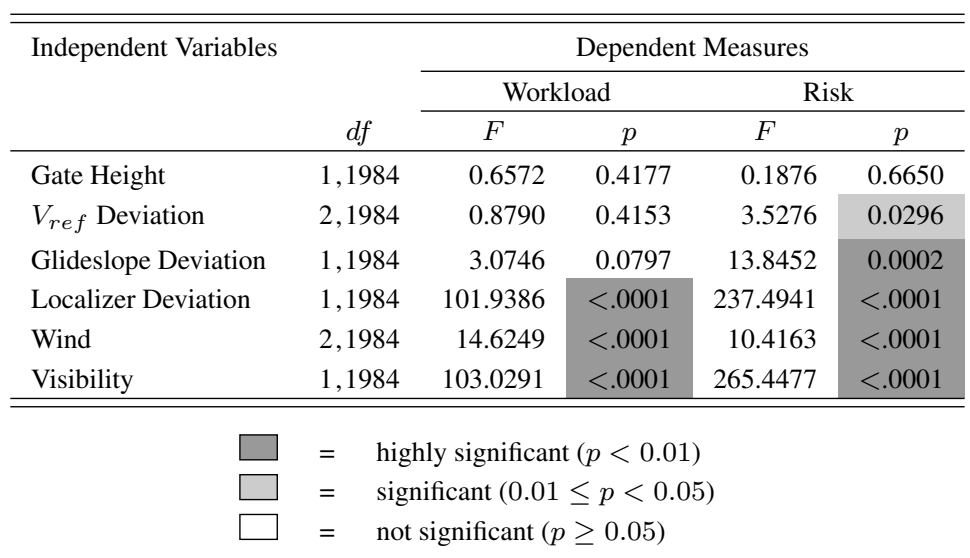



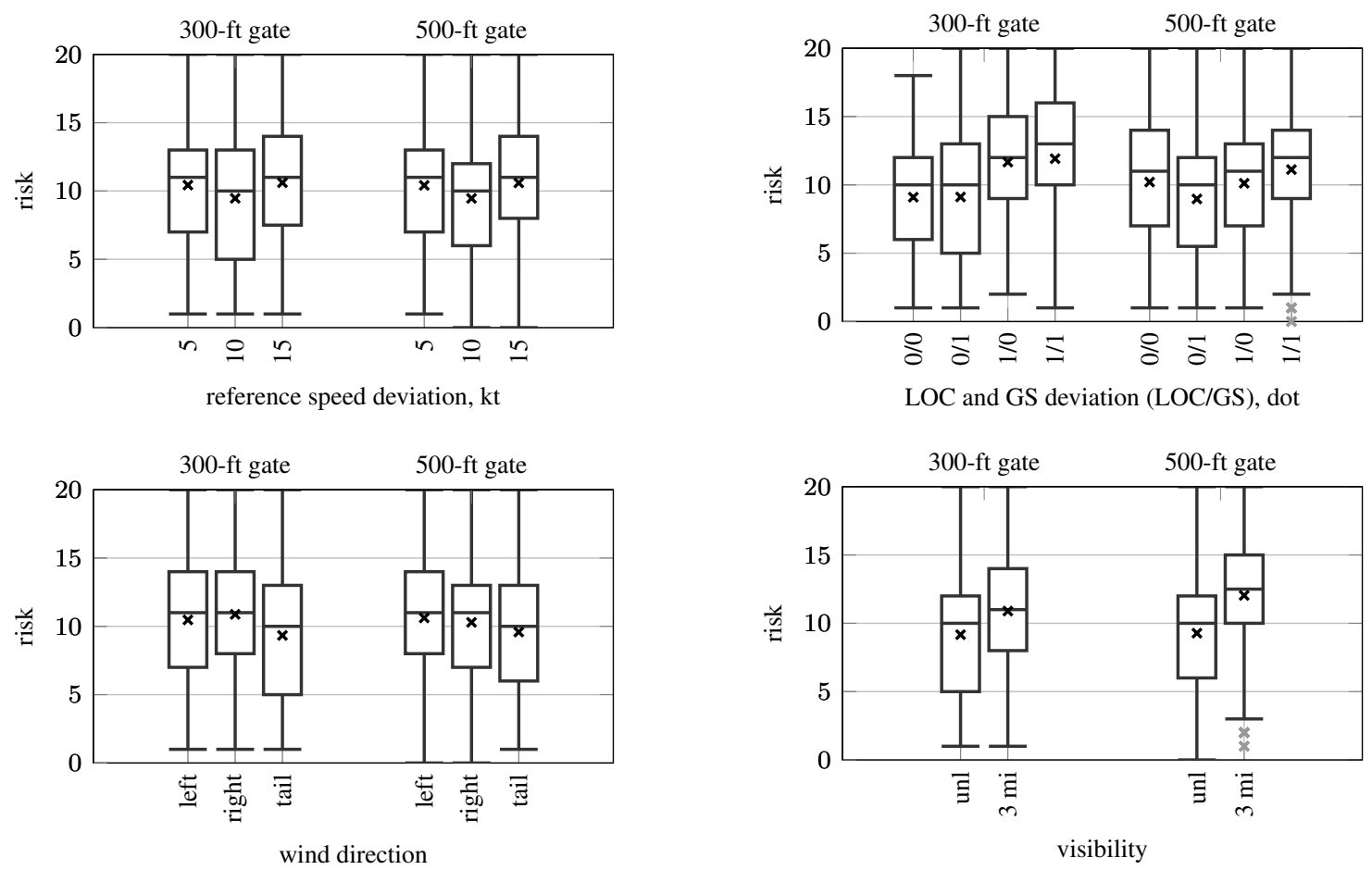

Figure 15. Effects of the independent variables on landing risk assessment (collapsed across PF and PM).

experiment, such as the localizer deviation and the visibility. This was in contrast to the workload and fatigue ratings which were more influenced by pilot role and run number compared to the primary independent variables.

A mixed model was constructed to determine if the independent variables introduced statistically significant differences in pilots' workload and risk responses. In the model, the experiment independent variables were treated as fixed effects and the pilot ID number was treated as a random effect. The results of the analysis are summarized in Table 5. The table provides the degrees of freedom $d f, F$, and $p$-values for the model. Landing risk scores are depicted in Fig. 15. Data are grouped by gate height. The remaining independent variables, reference speed deviation, localizer and glideslope deviations, wind condition, and visibility, are provided in the four subplots, respectively. As indicated by the shading in Table 5, localizer deviation, wind speed/direction, and visibility introduced highly significant differences in workload and perceived risk scores. Fig. 15 reveals that the risk associated with each landing was rated higher for the runs with a localizer deviation. Furthermore, higher landing risk scores were given in runs with a crosswind and limited visibility. Glideslope deviation also introduced a highly significant difference in landing risk. The landing risk was perceived to be higher when above the glideslope. Finally, $V_{\text {ref }}$ deviation introduced a significant difference in landing risk. Pilots perceived the landing risk to be lower in the $V_{\text {ref }}+10$ condition compared to the $V_{\text {ref }}+5$ and $V_{\text {ref }}+15$ conditions.

\section{IV.B.2. Go-Around Decision-Making}

Next, the tablet questionnaire asked pilots if they pressed the autopilot-disconnect button at any time during the previous run, indicating they would have gone around. The number of positive responses to this question (583) should have been equivalent to the number of autopilot-disconnect button presses (409); however, in 174 cases, pilots forgot to press the autopilot-disconnect button during the run but still indicated they would have gone around. The go-around decision questionnaire responses of the PF and the PM were used to construct a decision tree predictive model in $\mathrm{JMP}^{\circledR}$ in order to better understand the go-around thought process during the run.

When creating a decision tree, also known as partitioning or creating a partition model in JMP ${ }^{\circledR}$, the data set is recursively divided into smaller and smaller subsets using a tree structure according to relationships between the predictor and response variables. ${ }^{12}$ Decision trees generally handle large problems and data sets easily, are useful for exploring relationships without having a good prior model, and produce results in a format which makes them easily interpretable. The partition algorithm used by JMP ${ }^{\circledR}$ searches all possible splits of input variables and chooses optimum splits to best predict the output variable. The splits continue until the desired accuracy is reached. Finally, 


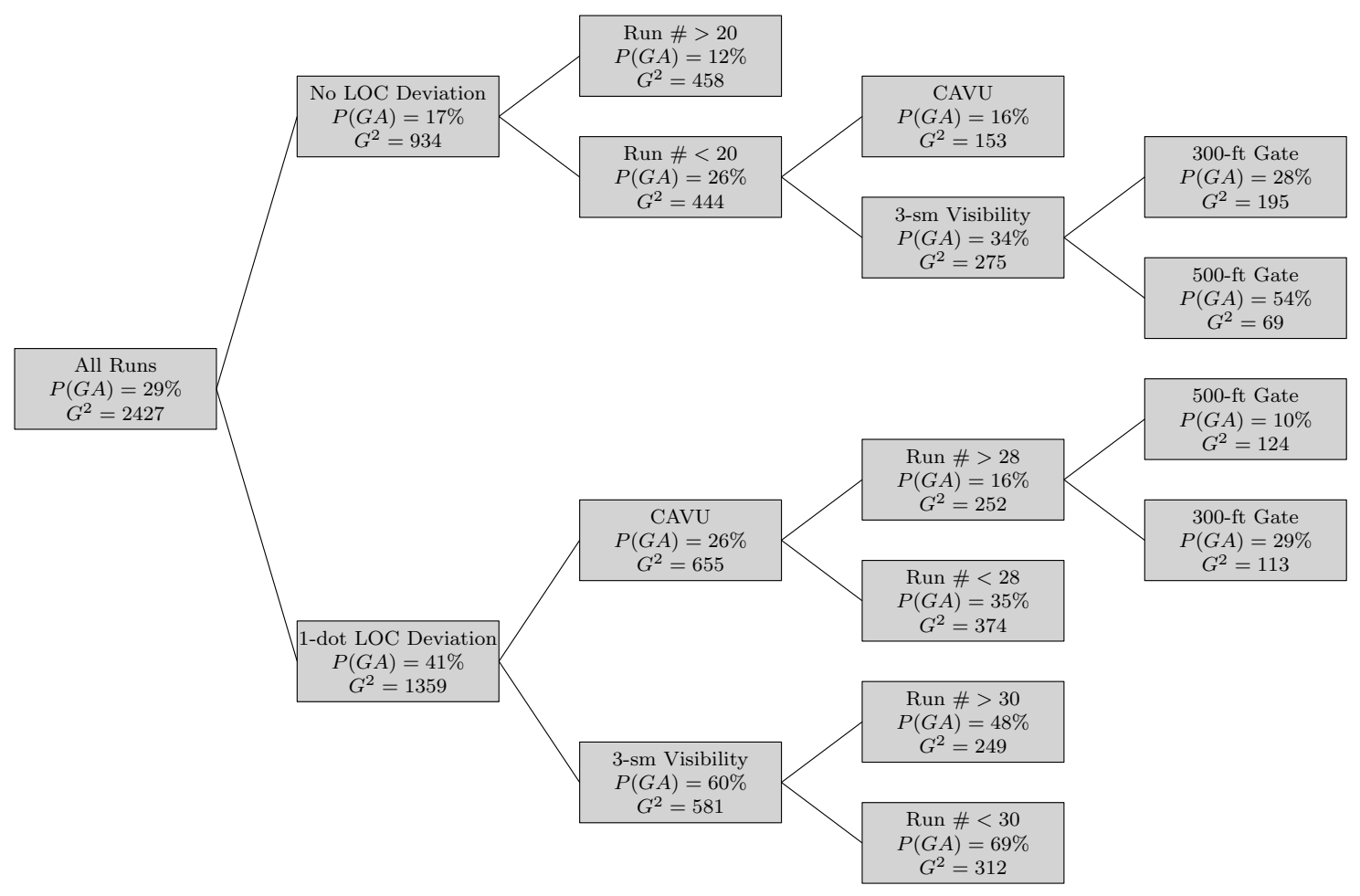

Figure 16. Decision tree for the go-around based on subjective data.

decision trees are able to handle data sets with a mix of both continuous and categorical input and output variables, making this predictive analytic technique ideal for the subjective questionnaire tablet data generated from the HITL simulation experiment.

The decision tree was constructed using the partition modeling platform in JMP ${ }^{\circledR}$, and is shown in Fig. 16, where $P(G A)$ refers to the conditional probability of a go-around based on the combinations of factors shown in the boxes, and $G^{2}$ refers to the likelihood-ratio chi-square value for the go-around decision, which is used by JMP ${ }^{\circledR}$ as one of the splitting criteria. ${ }^{12}$ In this case, the binary response variable was the go-around decision, and the predictor variables included in the analysis were the pilot role (PF or PM), run number, repetition, and the controlled variables in the experiment: gate height, localizer deviation, glideslope deviation, $V_{r e f}$ deviation, visibility, and wind speed/direction.

It can be seen from the decision tree that the primary drivers for the go-around decision were the localizer deviation and the visibility, where a localizer deviation of one dot and a visibility of three statute miles resulted in significant increases in the probability of a go-around compared to no localizer deviation and CAVU. It can also be seen that the run number had some effect on the pilot's decision to go around. The tree shows that higher run numbers decreased the probability of going around and lower run numbers increased the probability. This implies a learning effect during the simulation experiment, where pilots became more accustomed to the deviations given to them and felt more comfortable landing the aircraft in more risky situations over time. The decision tree also suggests an effect between the gate height and the go-around decision; however, it can be seen that this effect is different based on the localizer deviation and visibility conditions.

Splits in the data are automatically determined by JMP ${ }^{\circledR}$ in its partition modeling platform to construct the decision tree. ${ }^{12}$ Although only eight splits are shown in Fig. 16, a higher accuracy can be obtained by continuing to make splits in the tree and as

Table 6. Reasons for performing a go-around.

\begin{tabular}{lcccc}
\hline \hline & \multicolumn{3}{c}{ Percentage of Runs (Rank) } \\
Parameter & Pilot Flying & Pilot Monitoring \\
\hline Too Fast & $28.0 \%$ & $(5)$ & $27.5 \%$ & $(5)$ \\
Too Slow & $6.1 \%$ & $(13)$ & $2.7 \%(11)$ \\
High Rate of Descent & $40.5 \%$ & $(2)$ & $40.4 \%$ & $(3)$ \\
Low Rate of Descent & $3.4 \%$ & $(14)$ & $3.1 \%(14)$ \\
Above Glideslope & $40.5 \%$ & $(3)$ & $41.5 \%$ & $(2)$ \\
Below Glideslope & $21.0 \%$ & $(9)$ & $18.8 \%$ & $(8)$ \\
Localizer Deviation & $59.8 \%$ & $(1)$ & $47.7 \%$ & $(1)$ \\
Bank Angle & $14.9 \%$ & $(10)$ & $12.2 \%$ & $(10)$ \\
Power Setting & $7.1 \%$ & $(12)$ & $8.4 \%$ & $(12)$ \\
Wind & $38.9 \%$ & $(4)$ & $31.0 \%$ & $(4)$ \\
Visibility & $27.0 \%$ & $(6)$ & $21.3 \%$ & $(7)$ \\
Turbulence & $7.4 \%$ & $(11)$ & $4.5 \%(13)$ \\
Runway Length & $26.4 \%$ & $(7)$ & $22.7 \%$ & $(6)$ \\
Runway Condition & $22.0 \%$ & $(8)$ & $16.7 \%$ & $(9)$ \\
\hline \hline
\end{tabular}


additional variables are added as predictors. If one was to continue splitting the partition model created in this analysis, other variables are added to the model including glideslope deviation and wind speed/direction.

Pilots were also asked if they performed a go-around to select the reasons which influenced their decision. Pilots were allowed to select multiple parameters (Section III.E). The options pilots could select on the tablet questionnaire and the percentage of go-around runs that each parameter was selected are summarized in Table 6. The rank of each option is also given. Responses of the PF and the PM are provided separately. Table 6 indicates that the responses of the PF and PM are reasonably consistent. The top five reasons that pilots chose to perform a go-around were localizer deviation, high rate of descent, above glideslope, wind, and being too fast. Localizer deviation was also the primary go-around decision driver in the decision tree analysis (Fig. 16).

If the pilots chose to perform a go-around, the final two questions of the post-run questionnaire asked if the pilots' go-around decision would have been different if the runway was longer or had better braking action. In $0.7 \%$ of the runs, the PF said he/she would have landed if the runway had been longer, and in $0.3 \%$ of the runs the PF responded that he/she would have made a decision to land if the runway condition had been better. For the PM, these percentages were considerably higher, $4.5 \%$ and $3.5 \%$, respectively.

\section{Discussion}

The results of the experiment provided valuable data for evaluating the effect of environmental conditions on touchdown performance and for validating the conclusions of the study conducted in 2017. ${ }^{1}$ In this section, observations made on the importance of the environmental parameters on touchdown performance and the similarities and differences between the results of this study and the 2017 study are discussed.

\section{V.A. Effect of Environmental Conditions on Touchdown Performance}

In general, the results showed that the environmental parameters had a stronger influence on touchdown performance than the approach parameters (gate height, airspeed, glideslope deviation, and localizer deviation). Wind speed/direction had a strong effect on lateral touchdown point and longitudinal touchdown point and visibility had a highly significant effect on longitudinal touchdown point.

The significance of the effect of visibility on longitudinal touchdown point could be a reflection of whether the pilot was using the instrument landing system (ILS) or PAPI on approach. During a visual approach, the pilot was likely using line-of-sight and the PAPI as a guide; while during the low visibility condition, the pilot was more likely using the ILS. Because the ILS and PAPI do not coincide for SFO RWY 28R (Fig. 3), the aircraft would be aiming for a different point on the runway depending on the guidance being used, which could have manifested as an effect of visibility on longitudinal touchdown point.

The subjective data analysis revealed that visibility and wind direction/speed had a strong effect on workload and perceived landing risk. In fact, the environmental parameters had a stronger effect on perceived workload and risk than gate height, $V_{\text {ref }}$ deviation, or glideslope deviation. Of the approach independent variables, only localizer deviation had a comparable effect on workload and risk to the environmental parameters. The decision tree analysis showed that visibility also had a strong effect on the go-around decision.

The significance of the environmental parameters on both touchdown performance and pilots' perception of the landing highlight the importance of taking wind and visibility into account during an approach. For example, the results showed that a tailwind increased the longitudinal touchdown point distance from the threshold which could increase the risk of a runway overrrun. Additionally, wind and visibility strongly affected workload which could increase risk. These results show that if the approach parameters (airspeed, glideslope deviation, and localizer deviation) are within the upper and lower bounds of the test matrix, generally, the environmental parameters will have a stronger effect on the outcome than the approach parameters. This suggests that certain environmental conditions might warrant altered thresholds of the proposed go-around criteria in Table 1, either making them more conservative, or introducing variations based on actual wind and visibility conditions.

\section{V.B. Validation of Previous Results}

One of the objectives of this study was to validate the results of the HITL simulation experiment conducted in 2017 under various environmental conditions. ${ }^{1}$ The key findings of the 2017 study included the following: (1) touchdown performance was similar among the runs with a 300-ft and 500-ft starting gate; (2) $V_{\text {ref }}$ deviation had one of the stronger effects on touchdown performance; and (3) the reference speed and localizer deviations at the starting gate had the strongest and second strongest influence on the perceived risk and go-around decision, respectively. 
Generally, the results of this experiment were similar to those of the 2017 HITL experiment. The key finding of the 2017 study that touchdown performance was similar among the runs with a $300-\mathrm{ft}$ and $500-\mathrm{ft}$ starting gate was also observed in the study presented in the paper. The plots in Figs. 8 through 10 and the mixed-model analysis demonstrated that the gate height had minimal effects on touchdown performance. The only statistically significant effect of gate height on touchdown performance was on the longitudinal touchdown point measure. However, the difference in means was less than $50 \mathrm{ft}$, which is unlikely to have a significant effect on actual operations.

In this experiment, the range of $V_{\text {ref }}$ deviation values was smaller than what was used in the 2017 HITL experiment. That is, in this experiment, the maximum $V_{\text {ref }}$ deviation was $15 \mathrm{kts}$ while in the previous experiment the maximum deviation was $20 \mathrm{kts}$. Thus, as expected, $V_{\text {ref }}$ deviation had less of an effect on the results than the previous experiment because of the smaller range of values; however, a significant effect on sinkrate at touchdown was detected by the mixed-model analysis.

The mixed-model analysis on the subjective workload and risk scores showed some differences compared to the analysis performed on the the 2017 experiment results. Localizer deviation still had a highly significant effect on risk scores; however, the significance of the effect of $V_{r e f}$ deviation on risk was less than the previous experiment. One reason this could have occurred was the lowered upper range on the levels of $V_{\text {ref }}$ deviation used in this experiment compared to the 2017 experiment. Additionally, as shown by the results of the mixed-model analysis in Table 5, the newly introduced environmental variables had a highly significant effect on both risk and workload scores. This suggests that the environmental parameters tended to have a stronger influence on pilots' perception of workload and risk than most of the approach parameters used in the experiment.

Despite the fact that certain severe environmental conditions might require modified thresholds, the similarity in touchdown performance among runs with $300-\mathrm{ft}$ and $500-\mathrm{ft}$ starting gates in this experiment suggests that the conclusion of the previous experiment that a $300-\mathrm{ft}$ go-around decision gate could be acceptable still holds. This paper specifically explored the effects of approach state and environmental parameters on touchdown performance and goaround decision-making; it did not try to evaluate the usefulness of the proposed go-around criteria in Table 1 which is important. This was the purpose of the second day of the experiment which is discussed in a separate paper. ${ }^{13}$

\section{Conclusions}

The purpose of this study was to evaluate the effects of environmental conditions on touchdown performance under varying approach states and to validate proposed go-around criteria developed using data from a previously conducted study under these various environmental conditions. To accomplish this, an experiment was designed and carried out using B737-800 and A330-200 Level D full-flight simulators. Twenty-four pilots, 12 crews consisting of a captain and a first officer, each flew a full test matrix consisting of various approach and environmental independent variables. Each pilot also participated in the full test matrix as the pilot monitoring.

The results of the study showed that the environmental factors of wind speed/direction and visibility have a strong effect on touchdown performance. Specifically, wind had a highly significant effect on longitudinal and lateral touchdown point and a significant effect on sinkrate at touchdown. In fact, wind had a stronger effect on all three touchdown performance measures than any other variable in the study. Wind and visibility, along with localizer deviation, also had a strong effect on the pilots' perception of workload and risk. These results suggest that certain environmental conditions might warrant altered thresholds of the proposed go-around criteria. Furthermore, these findings highlight the importance of the environmental factors in the assessment of risk of unwanted outcomes on approach and landing.

This experiment validated the result of the previously conducted study that touchdown performance was similar among runs with a 300-ft and 500-ft starting gate. The few differences observed in the results between the two experiments can be explained by the reduced ranges used for approach variables and the strong influence of the environmental parameters on touchdown performance and subjective responses, and are unlikely to have operational significance. The similarity in touchdown performance among runs with $300-\mathrm{ft}$ and $500-\mathrm{ft}$ starting gates support the previous finding that lowering the go-around decision gate to $300 \mathrm{ft}$ might be acceptable.

\section{Appendix}

The full test matrix with 30 conditions is provided in Table 7. Additional runs of conditions $21,3,1$, and 2 (in that order) were used for training at the start of the first session and are not included in the repetition count in Table 7. 
Table 7. Experimental conditions.

\begin{tabular}{|c|c|c|c|c|c|c|c|}
\hline Condition & Repetitions & $\begin{array}{c}\text { Gate Height } \\
\mathrm{ft}\end{array}$ & $\begin{array}{c}V_{\text {ref }} \text { Deviation } \\
\text { kts }\end{array}$ & $\begin{array}{c}\text { GS Deviation } \\
\text { dot }\end{array}$ & $\begin{array}{l}\text { LOC Deviation } \\
\text { dot }\end{array}$ & $\begin{array}{c}\text { Wind } \\
\text { kts }\end{array}$ & $\begin{array}{c}\text { Visibility } \\
\text { sm }\end{array}$ \\
\hline 1 & 1 & 300 & +5 & 0.0 & 0.0 & left 20 & $\infty$ \\
\hline 2 & 1 & 300 & +5 & 0.0 & 0.0 & right 20 & 3 \\
\hline 3 & 1 & 300 & +5 & 0.0 & 0.0 & tail 10 & 3 \\
\hline 4 & 2 & 300 & +5 & 0.0 & 1.0 & left 20 & 3 \\
\hline 5 & 1 & 300 & +5 & 1.0 & 0.0 & left 20 & 3 \\
\hline 6 & 1 & 300 & +5 & 1.0 & 1.0 & right 20 & $\infty$ \\
\hline 7 & 2 & 300 & +10 & 0.0 & 0.0 & left 20 & 3 \\
\hline 8 & 2 & 300 & +10 & 0.0 & 1.0 & tail 10 & $\infty$ \\
\hline 9 & 2 & 300 & +10 & 1.0 & 0.0 & tail 10 & $\infty$ \\
\hline 10 & 1 & 300 & +10 & 1.0 & 1.0 & tail 10 & 3 \\
\hline 11 & 2 & 300 & +15 & 0.0 & 0.0 & right 20 & $\infty$ \\
\hline 12 & 2 & 300 & +15 & 0.0 & 0.0 & tail 10 & 3 \\
\hline 13 & 2 & 300 & +15 & 0.0 & 1.0 & right 20 & 3 \\
\hline 14 & 1 & 300 & +15 & 1.0 & 0.0 & right 20 & 3 \\
\hline 15 & 1 & 300 & +15 & 1.0 & 1.0 & left 20 & $\infty$ \\
\hline 16 & 1 & 500 & +5 & 0.0 & 0.0 & left 20 & 3 \\
\hline 17 & 2 & 500 & +5 & 0.0 & 1.0 & right 20 & $\infty$ \\
\hline 18 & 2 & 500 & +5 & 1.0 & 0.0 & right 20 & $\infty$ \\
\hline 19 & 1 & 500 & +5 & 1.0 & 1.0 & right 20 & 3 \\
\hline 20 & 1 & 500 & +5 & 1.0 & 1.0 & tail 10 & $\infty$ \\
\hline 21 & 1 & 500 & +10 & 0.0 & 0.0 & tail 10 & $\infty$ \\
\hline 22 & 1 & 500 & +10 & 0.0 & 1.0 & tail 10 & 3 \\
\hline 23 & 1 & 500 & +10 & 1.0 & 0.0 & tail 10 & 3 \\
\hline 24 & 2 & 500 & +10 & 1.0 & 1.0 & left 20 & $\infty$ \\
\hline 25 & 1 & 500 & +15 & 0.0 & 0.0 & right 20 & 3 \\
\hline 26 & 1 & 500 & +15 & 0.0 & 1.0 & left 20 & $\infty$ \\
\hline 27 & 2 & 500 & +15 & 1.0 & 0.0 & left 20 & $\infty$ \\
\hline 28 & 2 & 500 & +15 & 1.0 & 1.0 & left 20 & 3 \\
\hline 29 & 1 & 500 & +15 & 1.0 & 1.0 & right 20 & $\infty$ \\
\hline 30 & 1 & 500 & +15 & 1.0 & 1.0 & tail 10 & $\infty$ \\
\hline
\end{tabular}

\section{Acknowledgments}

The authors would like to thank the simulation engineers and support personnel who contributed to the experiments. We especially would like to thank Randall Cooper, Ricky Zoellner, and Larry Miller from the Flight Operations Simulation Laboratory at the FAA Mike Monroney Aeronautical Center for their valuable contributions in setting up and running the experiments. We would also like to thank Doug Rodzon for being a test pilot in the A330-200 simulator. We would like to thank Hossein Eghbali from the FAA William J. Hughes Technical Center for his continued program support. Finally, we would like to thank the pilots who participated in the experiments and experiment-planning workshops.

\section{References}

${ }^{1}$ Campbell, A. M., Zaal, P. M. T., Schroeder, J. A., and Shah, S. R., "Development of Possible Go-Around Criteria for Transport Aircraft," 2018 Aviation Technology, Integration, and Operations Conference, AIAA-2018-3198, American Institute of Aeronautics and Astronautics, June 2018.

${ }^{2}$ Federal Aviation Administration, "Mitigating the Risks of a Runway Overrun Upon Landing," Tech. Rep. AC 91-79A, 2014.

${ }^{3}$ Smith, J. M., Jamieson, D. W., and Curtis, W. F., "Why Are Go-Around Policies Ineffective? The Psychology of Decision Making During Unstable Approaches." 65th Annual FSF International Air Safety Seminar, The Presage Group, Oct. 2012.

${ }^{4}$ International Air Transport Association, “Unstable Approaches, Risk Mitigation Policies, Procedures and Best Practices,” Final report, 2016.

${ }^{5}$ Blajev, T. and Curtis, W., "Go-Around Decision-Making and Execution Project," Final report, Flight Safety Foundation, March 2017.

${ }^{6}$ Commercial Aviation Safety Team, "Runway Excursion - Flight Crew Landing Training," Safety Enhancement SE 216, June 2014.

${ }^{7} \mathrm{JMP}^{\circledR}$, Version 13, Cary, NC: SAS Institute, 1989-2007.

${ }^{8}$ MATLAB, "Version R2013b," The MathWorks Inc., 2013. 
${ }^{9}$ SAS Institute Inc., "Mixed Models and Random Effect Models," Tech. rep., Apr 2018.

${ }^{10}$ Littell, R. C., "Analysis of unbalanced mixed model data: A case study comparison of ANOVA versus REML/GLS," Journal of Agricultural, Biological, and Environmental Statistics, Vol. 7, No. 4, 2002, pp. 472-490.

${ }^{11}$ SAS Institute Inc., "JMP ${ }^{\circledR} 10$ Modeling and Multivariate Methods," Tech. rep., 2012.

${ }^{12}$ SAS Institute Inc., "JMP ${ }^{\circledR}$ Predictive and Specialized Modeling," Tech. rep., 2016.

${ }^{13}$ Campbell, A. M., Zaal, P. M. T., Schroeder, J. A., and Shah, S. R., "Pilot Evaluation of Proposed Go-Around Criteria for Transport Category Aircraft," 2019 Aviation Technology, Integration, and Operations Conference, AIAA-2019-3610, American Institute of Aeronautics and Astronautics, June 2019. 